DOI: https://doi.org/10.24164/prosiding.v3i1.18

\title{
JEJAK BUDAYA AUSTRONESIA DI KAWASAN PERKEBUNAN PENINGGALAN ZAMAN HINDIA BELANDA
}

\author{
Traces of Austronesia Culture in the Zone of the Heritage Platations \\ of Nederlands-Indie Era
}

\author{
Lia Nuralia \\ Balai Arkeologi Jawa Barat \\ Jalan Raya Cinunuk Km. 17 Cileunyi Bandung \\ E-mail: liabalar@yahoo.com
}

\begin{abstract}
Heritage plantations of the Dutch East Indies era are mostly found in West Java. The estate has a cultural footprint due to the colonization of Westerners in the Dutch East Indies. Colonization of a group of people into a new area that is already inhabited, resulting in cultural interaction. Local culture has developed with a touch of immigrant culture. Before the arrival of the West there had been cultural intrusion in the archipelago brought by the Austronesian-speaking community. There are three types of cultural intrusion, namely plant cultivation, water management, and permanent settlement patterns. In this paper only two types of cultural intrusion are discussed, namely plant culture and water management. Both cultural instructors have undergone renewal with the inclusion of elements of modern Western culture, brought by European colonists. Cultural reforms from traditional (Austronesian) and Modern (Western) cultures produce new cultures with new patterns of adaptation, evolution and cultural interaction.
\end{abstract}

Keywords: Traces of culture, Austronesian, plantations of Nederlandsch-Indie

\section{AbSTRAK}

Perkebunan peninggalan zaman Hindia Belanda banyak ditemui di wilayah Jawa Barat. Kawasan perkebunan memiliki jejak budaya akibat kolonisasi orang-orang Barat di Hindia Belanda. Kolonisasi sekelompok manusia ke wilayah baru yang sudah berpenghuni, mengakibatkan interaksi budaya. Budaya lokal mengalami perkembangan dengan sentuhan budaya pendatang. Sebelum kedatangan bangsa Barat telah terjadi intrusi budaya di kepulauan Nusantara yang dibawa oleh masyarakat penutur bahasa Austronesia. Ada tiga jenis intrusi budaya, yaitu budidaya tanaman, tata kelola air, dan pola pemukiman menetap. Dalam tulisan ini hanya dua jenis intrusi budaya yang dibahas, yaitu budaya tanaman dan tata kelola air. Kedua instrusi budaya tersebut telah mengalami pembaruan dengan masuknya unsur budaya modern Barat, yang dibawa para koloni Eropa. Pembaruan budaya dari budaya tradisional (Austronesia) dan budaya Modern (Barat) menghasilkan budaya baru dengan pola baru hasil adaptasi, evolusi, dan interaksi budaya.

Kata kunci: Jejak budaya, Austronesia, perkebunan zaman Belanda

\section{PENDAHULUAN}

W $\begin{aligned} & \text {.F. Wertheim mengungkapkan } \\ & \text { bahwa tanah jajahan adalah gabus }\end{aligned}$ tempat mengapungnya kesejahteraan negeri induknya. Perkebunan besar di Indonesia merupakan warisan Hindia Belanda, bentuk kolonisasi bangsa Barat (Belanda) paling menguntungkan negeri induk, sehingga sejarah kolonisasi di Indonesia adalah sejarah 
perkebunan itu sendiri (Kartodirdjo dan Djoko Surjo, 1990). Komoditas perkebunan besar di Priangan (Jawa Barat) pada abad ke-19 dan 20 pada umumnya adalah kopi, teh, kina, karet, kakao, dan lain sebagainya. Perkebunan besar di Bandung (Priangan) di antaranya: Bukit Unggul, Panglejar, Pangheotan, Cinyiruan, Kertamanah, Sinumbra, Rancabali, Rancabolang, Sedep, Malabar, Pasir Malang, Talun Santosa, Cikembang, Riung Gunung, dan Purbasari, dengan komoditas kopi, teh, kina, kakao, dan karet.

Pekebunan dengan komoditas kopi, teh, dan kina, masih meninggalkan jejak budaya perkebunan. Jejak budaya berupa material culture dan immaterial culture, menunjukkan proses akulturasi antara budaya pendatang dan lokal yang menghasilkan budaya baru. Budaya pendatang merupakan budaya modern Barat yang dibawa oleh orangorang Barat (Belanda). Budaya lokal adalah budaya tradisional Indonesia yang berakar dari kebudayaan Austronesia.

Kebudayaan Austronesia menjadi akar peradaban kebudayaan Indonesia (Munandar, 2012). Kebudayaan Austronesia adalah istilah ciptaan para sarjana. Para ahli mengungkapkan migrasi orang-orang Austronesia terjadi sekitar tahun 6000 SM - awal tarikh Masehi. Mereka tinggal

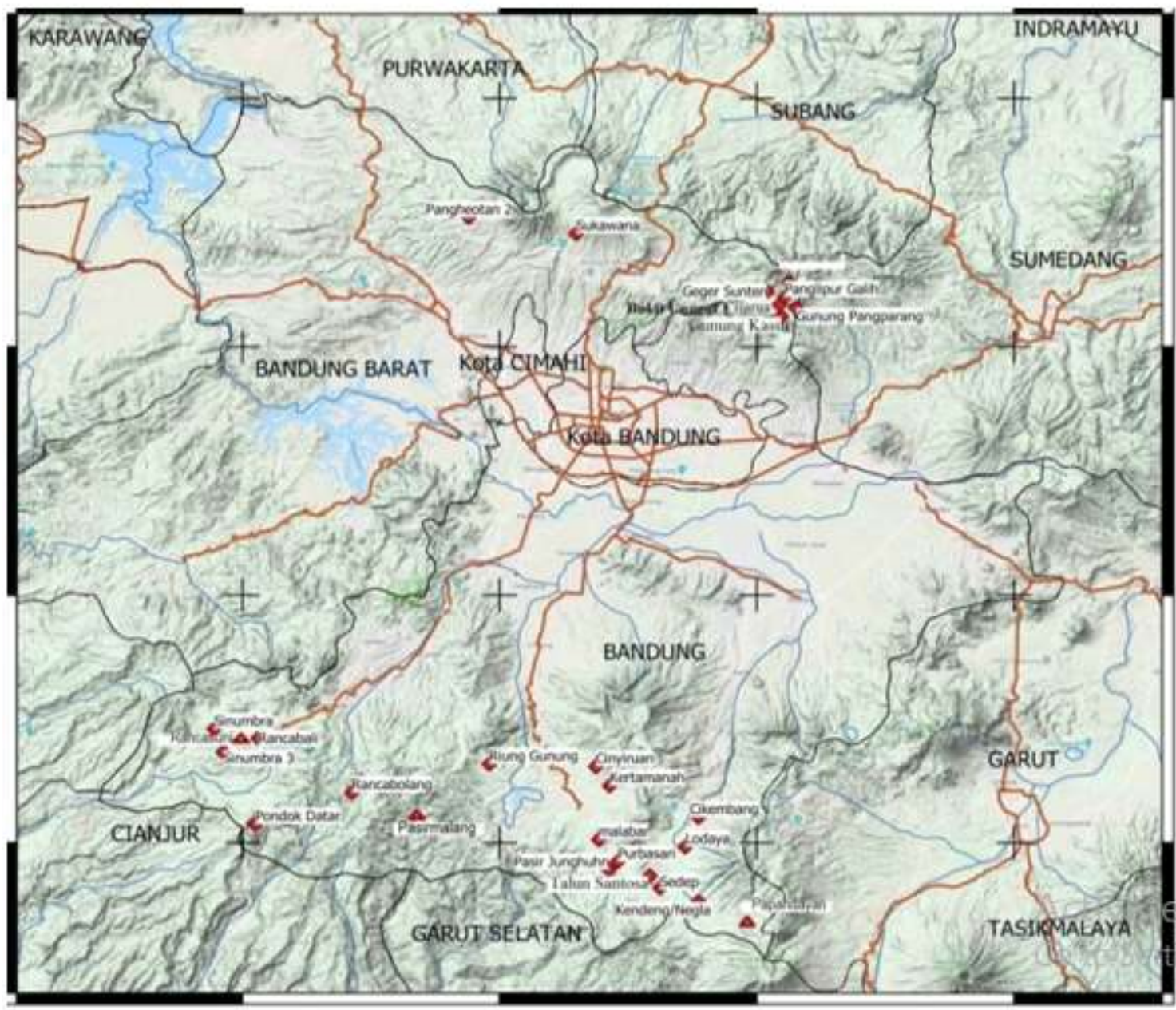

Gambar 1. Peta Denah Lokasi Perkebunan Peninggalan Hindia Belanda di Bandung (Peta Hasil Foto Drone Mix Google Terrain, oleh Azhar Rachman. Modifikasi Lia Nuralia, 2019). 


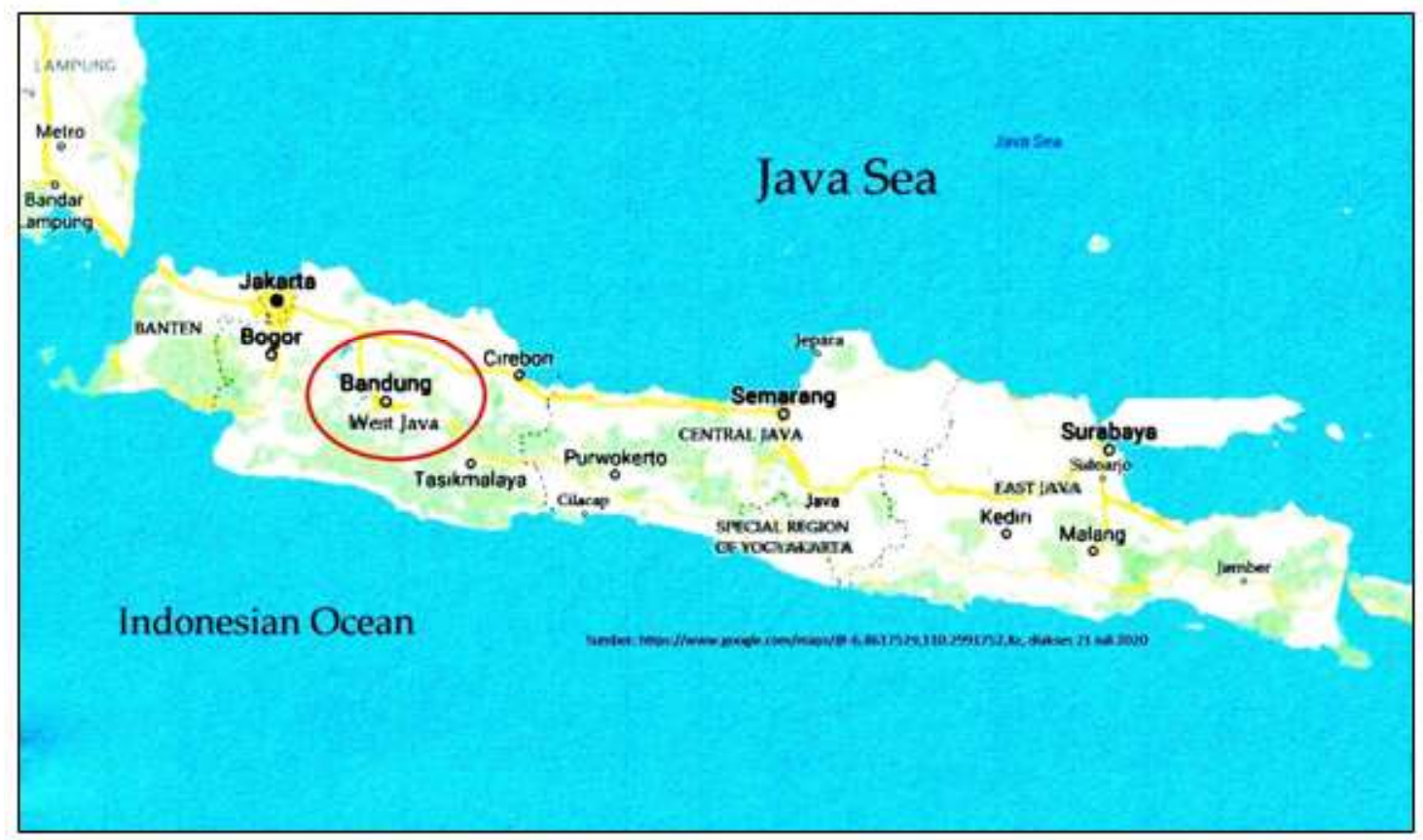

Gambar 2. Peta Lokasi Penelitian di Bandung Jawa Barat dalam Peta Pulau Jawa-Indonesia (Sumber: https://www.google.com/maps/@-6.8617529,110.2991752,8z, diakses 21 Juli 2020. Modifikasi Lia Nuralia, 2020)

dan menetap di beberapa wilayah di Asia, tetapi tempat pastinya masih diperdebatkan. Perkiraan awal menetap di wilayah Yunan Cina Selatan, menyebar ke daerah-daerah di Asia Tenggara. Diaspora Orang-orang Austronesia terjadi pada rentang waktu sebagai berikut.

- 3000-2500 BC: Taiwan dan kepulauan Filipina.

- 2500 S : Sulawesi, Kalimantan dan pulau-pulau lain.

- 2000 SM: Maluku dan Papua; dari daratan Asia Tenggara ke Semenanjung Malaysia dan pulau-pulau bagian barat Indonesia.

- $\quad$ Pulau-pulau Pasifik hingga tahun 500 SM - awal tarikh Masehi.

(H.Kern, ahli linguistik; W.Schmidt, antropolog; P.V.van Stein Callenfels, Robert von Heine Geldern, H.O.Beyer; dan R.Duff, arkeolog (Munandar, 2012)
Sebagian besar masyarakat awam memahami Kebudayaan Austronesia sebagai budaya masa prasejarah. Akan tetapi, fakta menampilkan bahwa budaya Austronesia berkembang dan berlanjut sampai sekarang. Masa klasik Hindu-Buddha, masa pengaruh Islam dan kolonial, sampai masuk era modern sekarang. Kebudayaan Austronesia dibawa dan disebarkan oleh masyarakat penutur bahasa Austronesia. Masuk melalui intrusi budaya, yaitu budidaya tanaman, tata kelola air, dan pola pemukiman menetap. Jejak kebudayaan Austronesia dapat ditelusuri melalui kebudayaan tradisional Sunda pada masyarakat, yang mendapat pengaruh budaya Barat. Apa dan bagaimana jejak Kebudayaan Austronesia masyarakat perkebunan di Bandung, menjadi permasalahan pokok dalam tulisan ini.

Metode penelitian yang digunakan adalah desk research terhadap Laporan Hasil Penelitian Arkeologi (LHPA) 2019, 
dilengkapi sumber arsip kolonial (Belanda). Kemudian dilakukan studi literatur terhadap buku, artikel jurnal, serta hasil wawancara selama penulisan dilakukan.

\section{PEMBAHASAN}

\section{Budidaya Tanaman di Perkebunan}

Budidaya tanaman teh, kopi, dan kina memiliki caranya sendiri-sendiri. Budidaya tanaman di perkebunan kina Bandung menyangkut cara penanaman dan perkembangbiakan tanaman.

Penanaman kina dilakukan di lahan miring di lereng gunung (kemiringan $\pm 30^{\circ}-45^{\circ}$ ) dengan suhu udara rendah (antara 13,5 $-21^{\circ} \mathrm{C}$ ), dalam iklim tropis basah (lahan kebun kina $\pm 800-2.000 \mathrm{~m}$ dpl; ketinggian optimum lahan kina 1.400-1.700 m dpl) (de Kinacultuur, No. Invetaris: 835).
Pada zaman Belanda penyediaan lahan dilakukan dengan membuka hutan, menebang pohon dan mencabut akar. Penataan tanah dengan cara cut \& fil lahan, sehingga dapat dibuat lahan terasering (Wulandari, 2019). Proses cut \& fill adalah satu proses yang dilakukan oleh ahli untuk meratakan tanah dengan cara mengeruk satu bagian lahan berbukit, kemudian mengurug atau menimbun bagian lain dengan tanah kerukan tersebut sampai menjadi lahan kebun yang rata (https://www.lamudi.co.id/ istilah-properti/, diakses 11 Maret 2020). Pengolahan tanah dilakukan dengan tenaga manusia, dilanjutkan dengan mesin ketika kemajuan teknologi terjadi (lihata Gambar $3)$.

Perkembangbiakan tanaman kina dengan cara tanam biji dan stek sambung telah dilakukan sejak dahulu di Kebun

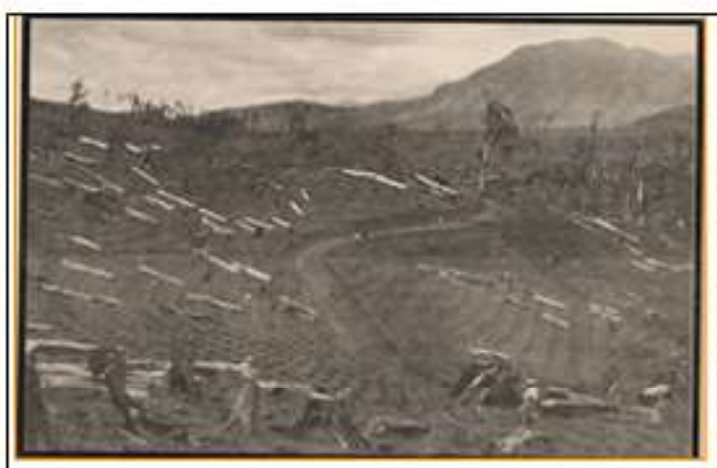

a. Penediasn lahan menebang pohon di hutan

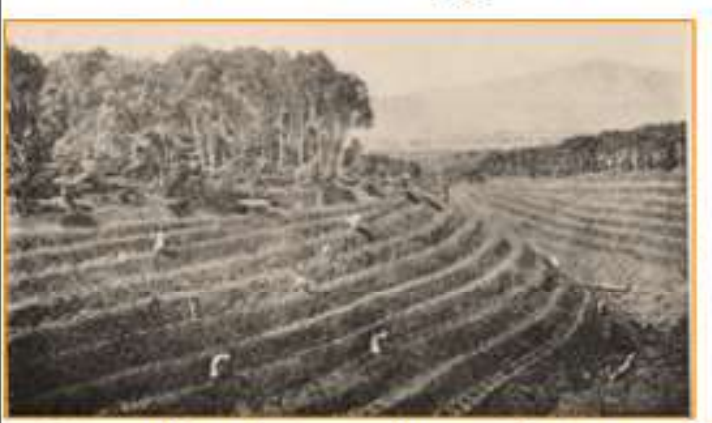

c. Lahan miring berterasering untuk tanaman kina

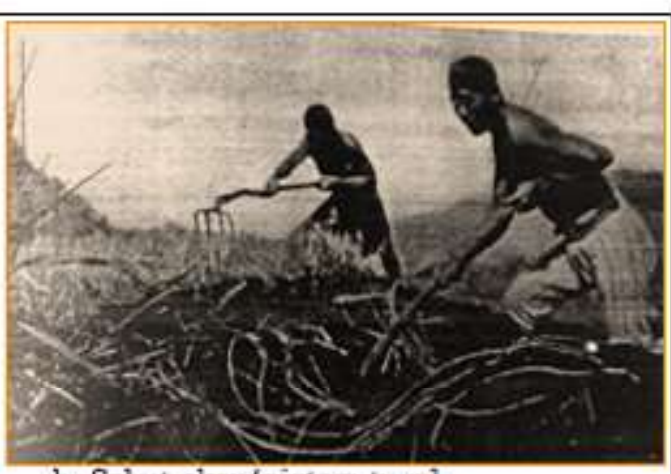

b. Sabut alcar/sistem tugal

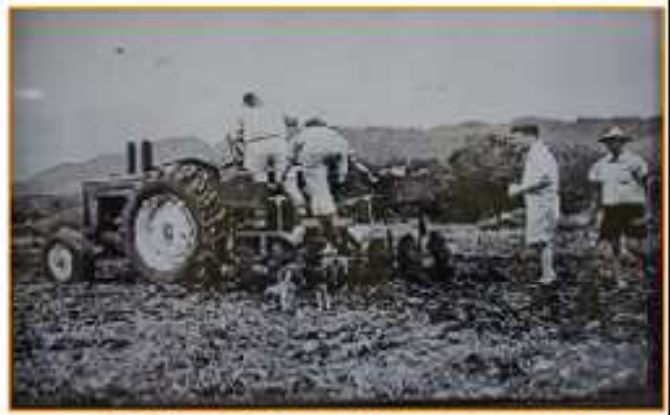

d. Mengolah tanah dengan mesin

Gambar 3. Foto Lama Penyediaan Lahan (Sumber: Van Dr. C. JJ. Van Gall en C. Van De Koppel: 1946, 17 (Sumber: Dok. Rumah Manajer Perkebunan Kertamanah, 2019). 


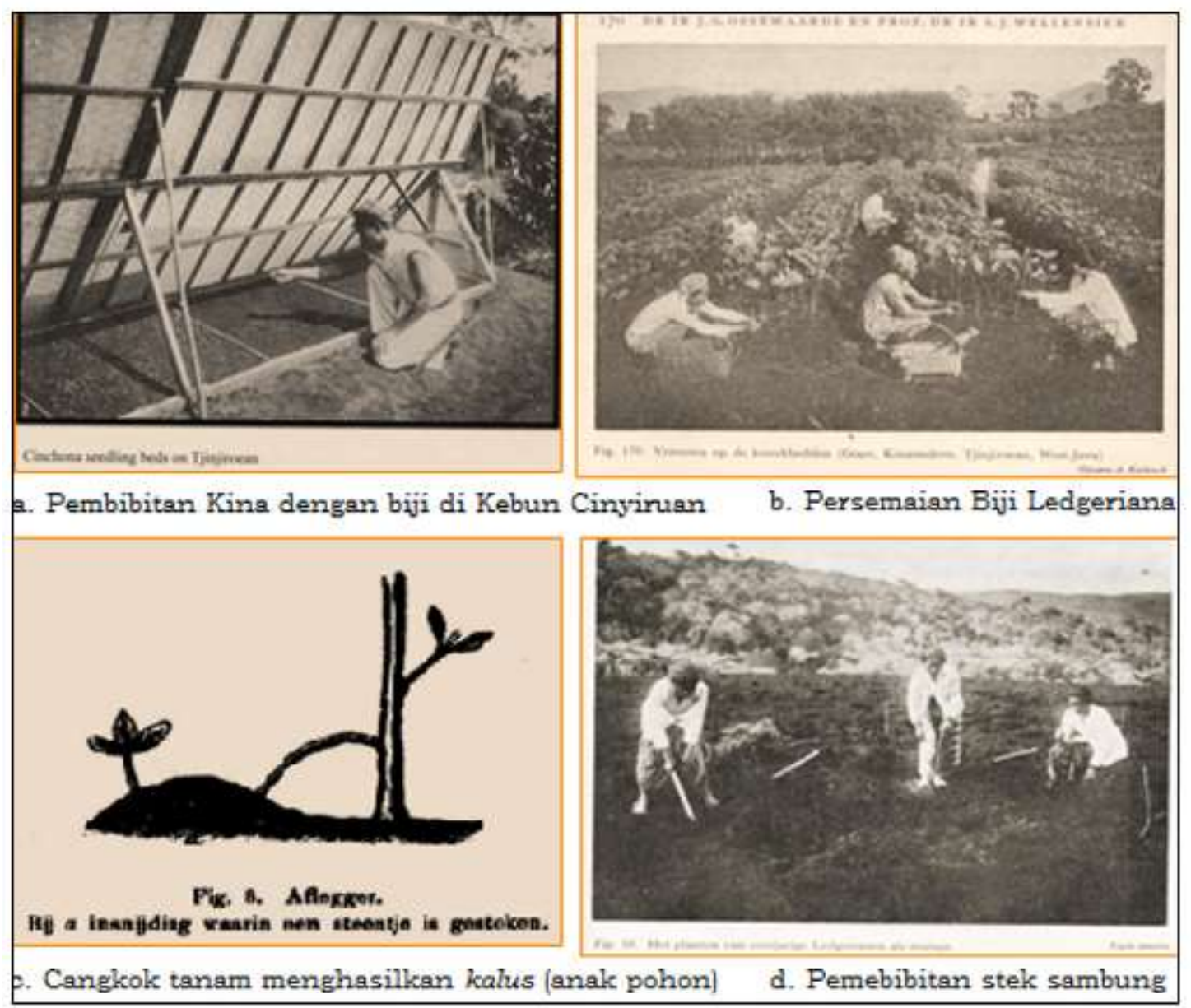

Gambar 4. Foto Lama Perkembangbiakan Pohon Kina (Sumber: Picture from The Archives of the Royal Tropical Museum Amsterdam; Van Dr. C. JJ. Van Gall en C. Van De Koppel, 1946: 17 (Sumber: Dok. Rumah Manajer Kertamanah, 2019).

Bukit Unggul (wawancara dengan Sider Afdeling Bukit Unggul. 2018), Kebun Cinyiruan dan Kebun Kertamanah (lihat Gamabr 4). Selain itu, pernah juga dilakukan metode perkembangbiakan Cangkok Tanam dari batang pohon bagian bawah yang menghasilkan kalus (anak pohon) (lihat Gambar 4 bagian b) (C.J.J Van Hall en C.Van De Koppel, 1946: 17; Nuralia, 2019: 169). Pada masa sekarang ini pohon kina dikembiakkan dengan cara stek sambung, seperti yang dilakukan di Kebun Bukit Unggul (Nuralia, 2019: 165168).

\section{Tata Kelola Air di Perkebunan}

\section{- Pembangkit Listrik Tenaga Mikro Hidro (PLTMH)}

Tata kelola air melalui PLTHM merupakan penghasil energy listri yang telah modern, dengan sumber energy berpola tradisional. Gabungan cara modern dan tradisional menjadi tata kelola air yang ada di perkebunan besar sejak zaman Hindia Belanda. Sumber energi listrik tersebut merupakan energi terbarukan sebagai bahan alternatif, untuk mengurangi pemakaian bahan bakar fosil dalam pembangkitan 


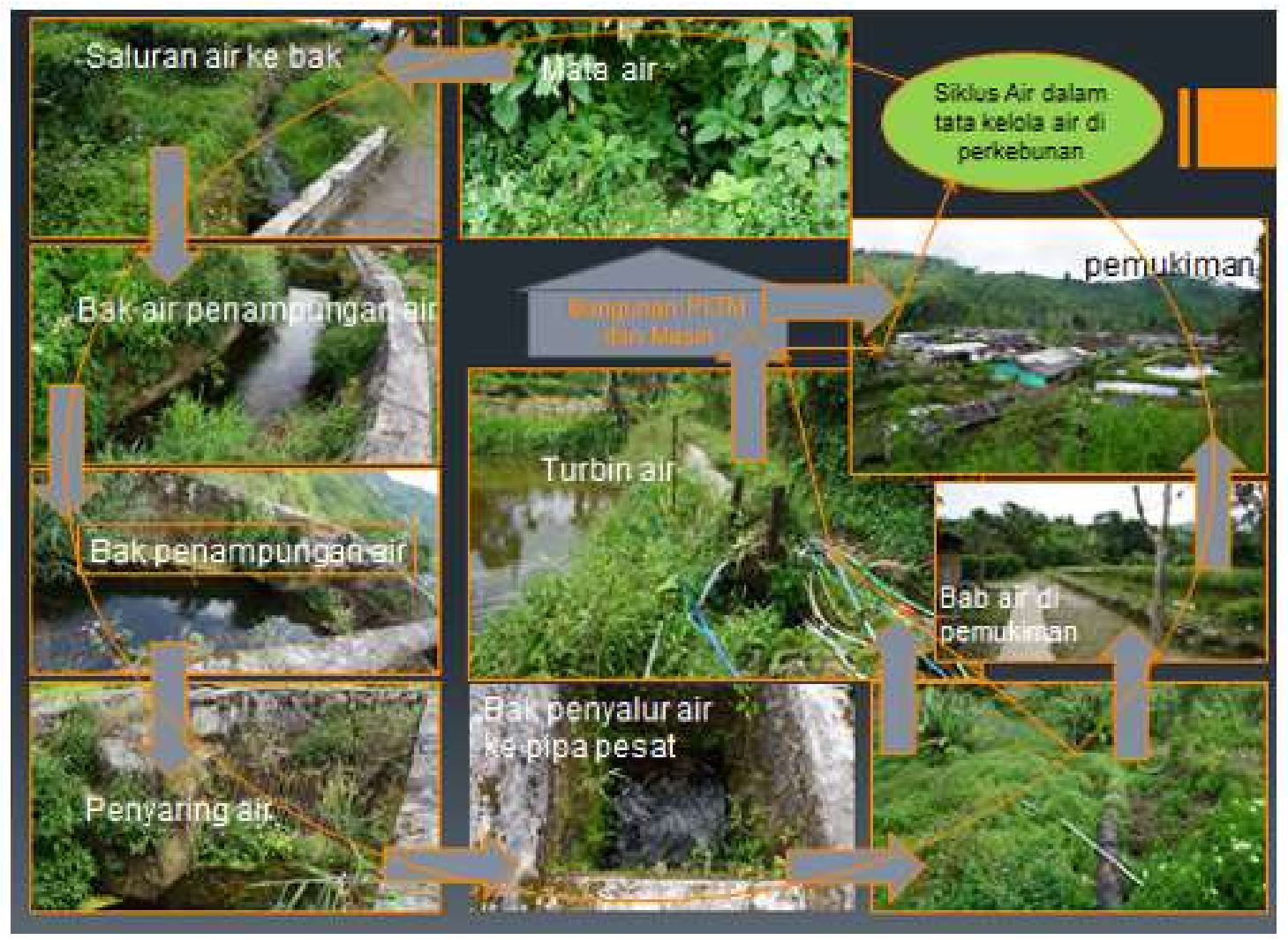

Gambar 5. Siklus pemanfaatan sumber mata air (bukit) sebagai Tata Kelola Air di Emplasemen Permukiman Afdeling Sinumbra 3 (lembah) (Sumber: Dok. Balai Arkeologi Jawa Barat, 2019. Modifikasi Lia Nuralia, 2020).

energ listrik. Sumber energi terbarukan tersebut tersebar sesuai potensi daerah di Indonesia, seperti potensi air, angin, gelombang laut, panas bumi, dan lainnya (Corio, Kiki Khananda, Khansa Salsabila S, 2019: 97). Potensi sumber air di perkebunan di pedalaman (alam pegunungan) adalah sumber mata air dan sungai, baik di pedataran lembah maupun yang mengalir di pedataran lereng gunung (bukit).

PLTMH merupakan pembangkit listrik skala kecil yang menggunakan tenaga air sebagai tenaga penggeraknya. Secara teknis memiliki tiga komponen utama, yaitu generator, turbin, dan air (sebagai sumber energi). Kemudian komponen penting selanjutnya adalah pipa pesat (Winarno dan
Amdhika Putra Widyadharma, 2018: 215). Air yang dapat digunakan seperti saluran irigasi, sungai, air terjun alam dengan cara memanfaatkan tinggi terjunan dan junlah debit air. Untuk daerah perkebunan di pegunungan, sumber energy air yang digunakan untuk menggerakan turbin PLTMH adalah mata air di atas bukit (mata air atau cai nyusu dalam istilah Sunda).

Tata kelola air di perkebunan memanfaatkanketinggian lahan, sumbermata air, dan danau alami. Lokasi emplasemen permukinan Sinumbra 3 (Kebun Sperata) berada di lembah dan dikelilingi bukit-bukit. Pada salah satu bukitnya terdapat sumber mata air (cai nyusu Sinumbra) (Gambar 5). Pembangkit Listrik Tanaga Mikrohidro (PLTM) didirikan dengan membuat bak 


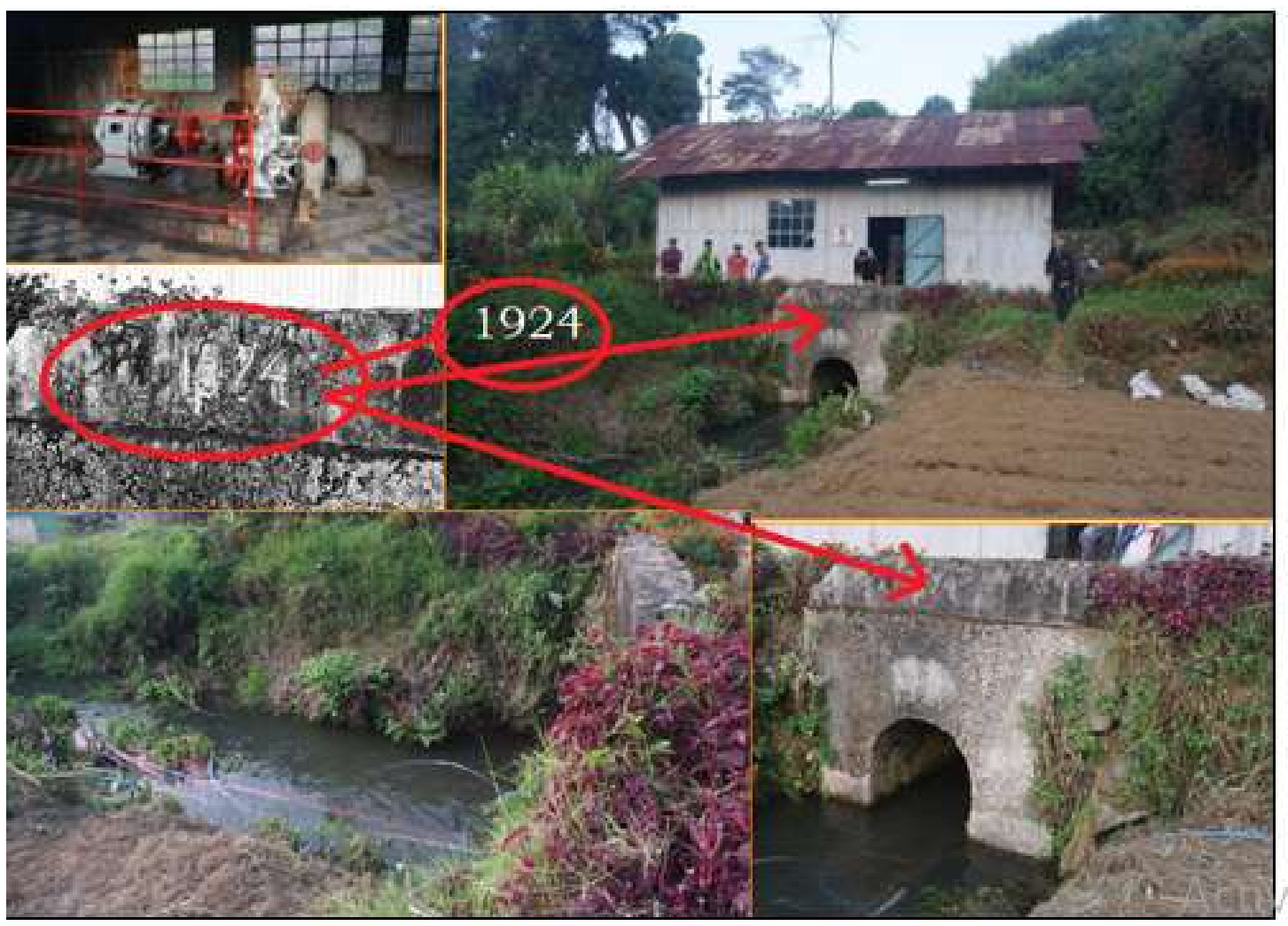

Gambar 6. PLTMH Papandayan Perkebunan Sedep, Kertasari - Bandung - Jawa Barat (Sumber: Dok. Balai Arkeologi Jawa Barat, 2019. Modifikasi Lia Nuralia, 2020).

air dekat sumber mata air, kemudian menyalurkan air melalui pipa pesat. Ketika air sampai di lembah (pemukiman) saluran air dibagi dua, satu ke turbin untuk mengubah tenaga air menjadi tenaga listrik, satu lagi ke bak penampungan untuk keperluan air sehari-hari di pemukiman. Kemudian PLTMH perkebunan yang masih ada sampai sekarang dan masih difungsikan adalah PLTMH Papandayan Perkebunan Sedep (Gambar 6).

Beberapa komponen PLTMH sebagai berikut.

- Generator: alat yang memproduksi energy listrik dari sumber energy mekanik, dengan menggunakan induksi elektromagnetik;

- $\quad$ Turbin: mesin berputar yang mengambil energy dari aliran fluida. Fluida yang bergerak menjadikan baling-baling berputar dan menghasilkan energy untuk menggerakan rotor;

- Air;

- Pipa pesat: digunakan untuk memutar turbin; dan

- Metode suction (hisap): metode yang mengambil prinsip hukum Bernoulli, yang dipilih untuk menghitung aliran air dengan harapan dapat menghasilkan debit yang kontinyu. (Winarno dan Amdhika Putra Widyadharma, 2018: 213).

\section{- Tata Kelola Air Embung}

Embung atau cekungan penampung (retention basin) merupakan cekungan yang digunakan untuk mengatur suplai aliran air hujan, serta untuk meningkatkan kualitas air di badan air yang terkait (sungai, 
danau). Embung digunakan untuk menjaga kualitas air tanah, mencegah banjir, dan digunakan petani untuk mengairi lahan di musim kemarau. Embung bisa disebut juga sebagai kolam penampungan air dari sumber mata air. Apabila musim hujan air berlimpah tidak membuat lahan sawah atau lahan lainnya terendam. Kelebihan air tersebut akan ditampung oleh embung. Ketika musim kemarau tiba dan air dari irigasi tidak mencukupi, embung dapat dimanfaatkan secara efektif dan efisien. Lahan yang membutuhkan siraman air dapat mengambilnya atau menerima aliran air dari embung (Wawancara dengan Bagian Umum Kebun Malabar, Bapak Asep, 2019).

Air embung merupakan waduk berukuran mikro yang dibangun untuk menampung kelebihan air hujan ketika musim hujan. Misalnya aliran 2 sungai yang dibendung menjadi sebuah waduk. Air embung bisa digunakan sebagai sumber energy untuk menggerakkan turbin pembangkit listrik tenaga air dengan metode hisap untuk menghasilkan kontinuitas aliran air sesuai debit yang diperlukan, sehingga dapat dimanfaatkan masyarakat untuk kebutuhan sehari-hari (Winarno dan Amdhika Putra Widyadharma, 2018: 215).

Embung yang didirikan di perkebunan sangat memberi manfaat bagi tanaman komoditas perkebunan, bagi lahan sawah dan kebun, serta memenuhi kebutuhan air masyarakat perkebunan. Embung perkebunan yang masih ada jejaknya, seperti Embung Situ Sinumbra (Gambar 8). Air Embung Situ Sinumbra dahulunya dialirkan dan ditampung di Situ Al-Nafi, kemudian air masuk ke Situ Bayingbong dan didistribusikan ke rumah-rumah warga masyaraat perkebunan khususnya, dan masyarakat umum lainnya. Selanjutnya air bekas pake ditampung di pembuangan di Situ Bale Gede untuk menggerakan turbin

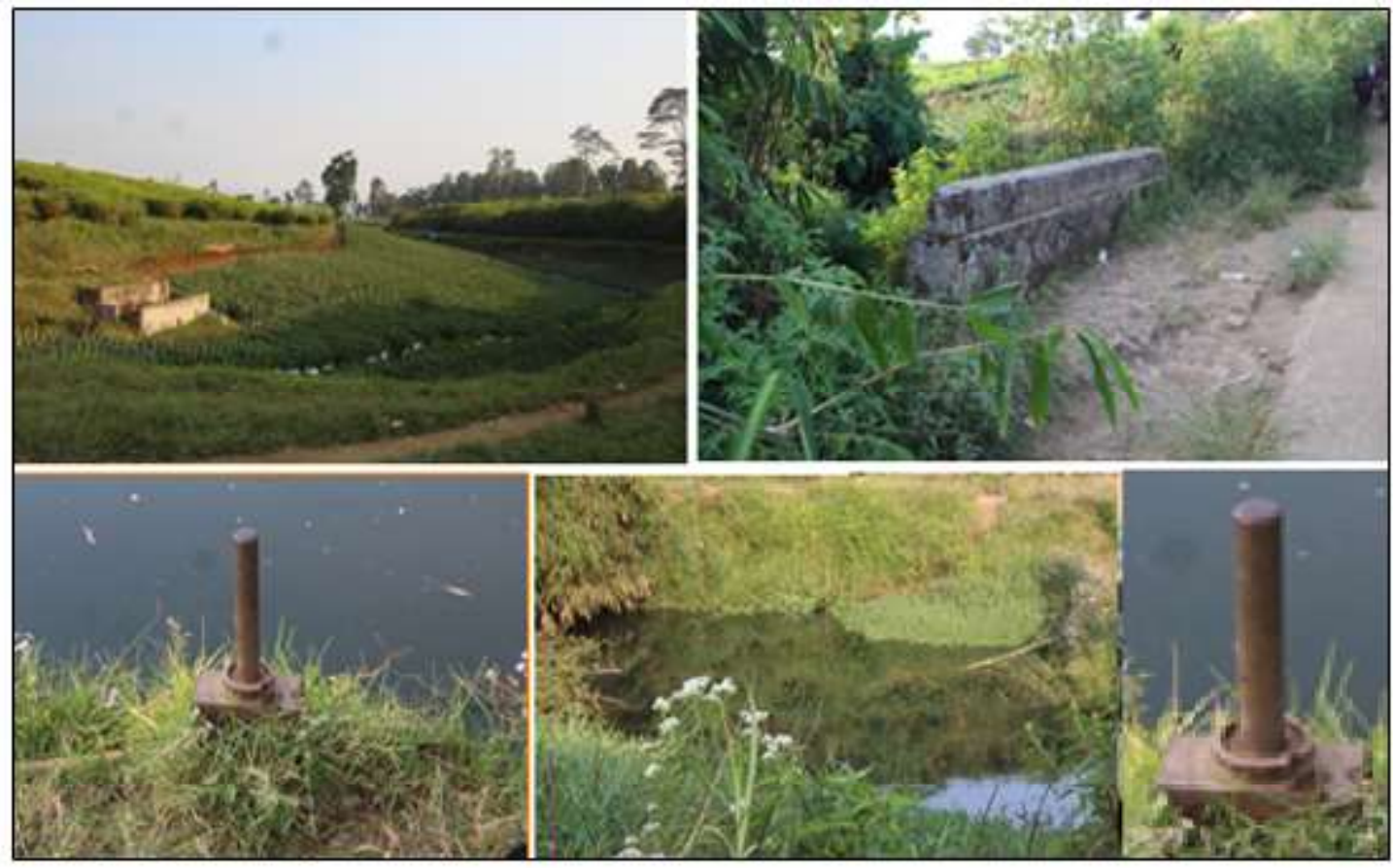

Gambar 7. Bekas Embung Malabar di Bandung-Jawa Barat (Sumber: Dok. Balai Arkeologi Jawa Barat, 2019. Modifikasi oleh Lia Nuralia, 2020). 


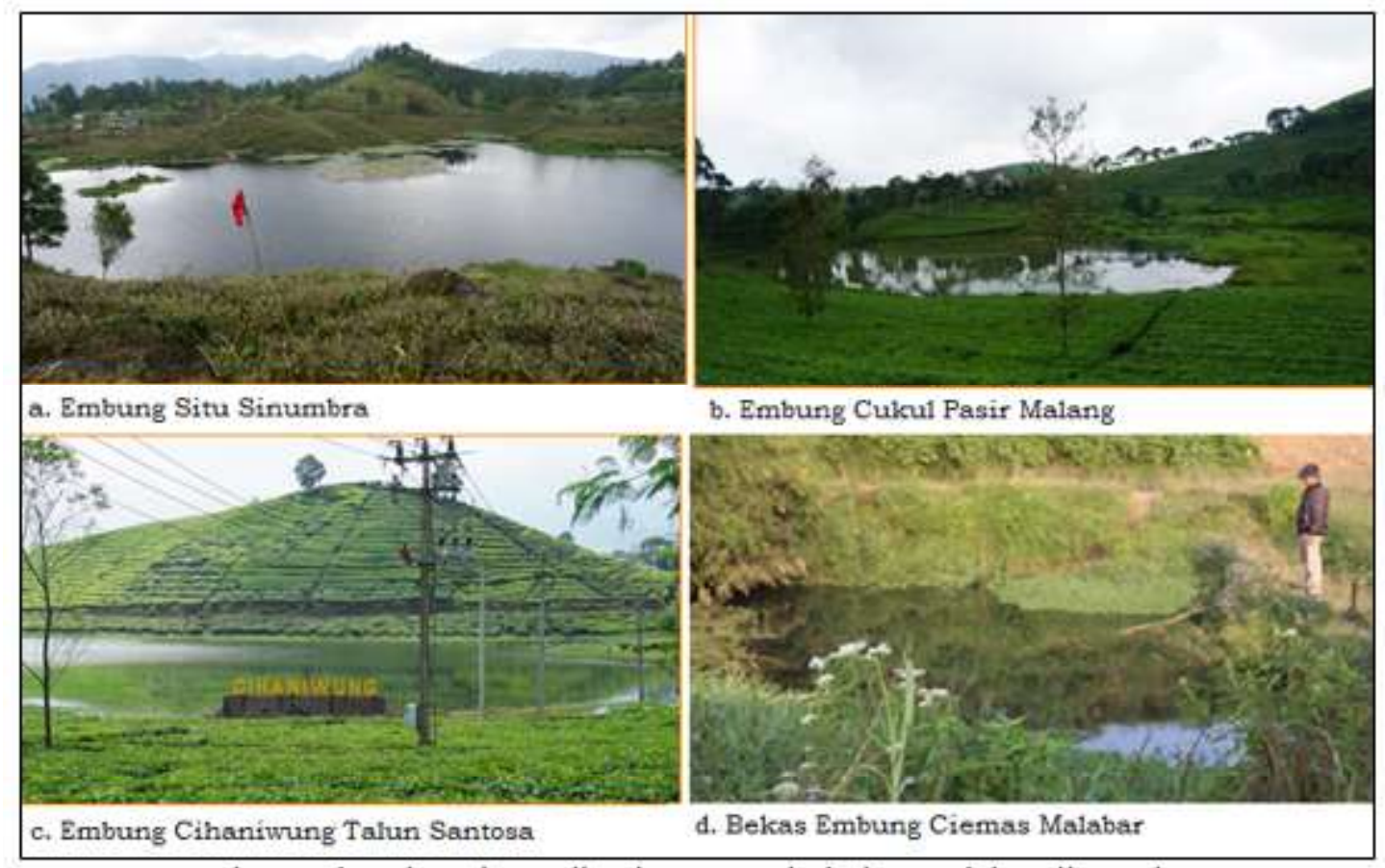

Gambar 8. Embung Situ Sinumbra, Cihaniwung, Cukul, dan Malabar di Bandung-Jawa Barat (Sumber: Dok. Balai Arkeologi Jawa Barat, 2019. Modifikasi oleh Lia Nuralia, 2020).

PLTM Sukaati dan mengalir ke Sungai Cipelah (Wawancara dengan Asisten Kepala Perkebunan Sinumbra, Bapak Yadi, April 2019).

Jejak embung perkebunan lainnya adalah Embung Ciemas di Kebun Malabar (Gambar 7). Pada zaman dahulu air Embung Ciemas bermanfaat untuk memenuhi kebutuhan air minum, MCK, serta sawah dan kebun para pekerja perkebunan. Sekarang ini sudah tidak ada lagi, yang tersisa hanya kolam kecil atau genangan air berupa cekungan, jembatan, besi bekas pintu air/bekas turbin, dan hamparan lahan hijau. Embung Kebun Malabar yang masih ada dan masih digunakan sampai sekarang adalah Embung Cicoledas, terletak di jalan menuju Cikembang (Wawancara dengan bagian adaministrasi, Ramdhan, 3 Maret 2020).

Embung perkebunan lainnya di antaranya Embung Cihaniwung yang ada di Kebun Talun Santosa, dan Embung Cukul dekat Kebun Pasir Malang masih digunakan sampai sekarang untuk kebutuhan air dan sebagai tempat rekreasi (Wawancara dengan Asisten Kepala Perkebunan Talun Santosa, 2019). Kemudian Embung situ Kinceuh di Kebun Kertamanah, sedangkan di jalan menuju Cikembang mah bernama Embung Cicoledas milik Kebun Malabar. Sumber mata airnya dari Sungai Kinceuh, bak penampungannya juga di dekat Sungai Kinceuh, sampai sekarang masih digunakan untuk keperluan air minum, keperluan sehari hari MCK, dan keperluan pabrik. Keperluan energi listrik Kebun Kertamanah dahulu dipasok dari Kebun Malabar. Ada bak tampungnya dan sebelum di buang ke sungai ada kolam resapan.

\section{SIMPULAN}

Jejak kebudayaan Austronesia dapat ditelusuri melalui kebudayaan tradisional Sunda pada masyarakat perkebunan di 
Bandung Jawa Barat. Jejak yang ada sudah mendapat pengaruh budaya Barat, di antaranya budidaya tanaman dan tata kelola air. Budidaya tanaman menyangkut penyediaan lahan, pembibitan dan perkembangbiakan, serta penanaman hasil pembibita kina di lahan kebun. Pada sekarang ini, budidaya tanaman kina hanya ada di Kebun Bukit Unggul.

Tata kelola air di perkebunan ada dua jenis, yaitu Pembangkit Listrik Tenaga Mikro Hidro (PLTHM) dan Embung. PLTHM perkebunan zaman Belanda yang masih aktif sampai sekarang adalah PLTHM Papandayan Perkebunan Sedep, sedangkan PLTHM Sinumbra ditemukan jejaknya berupa mata air, bak penampungan air, pipa pesat, dan bekas turbin air. Sementara itu, Embung yang masih beroperasi sampai sekarang adalah Embung Situ Sinumbra (Sinumbra), Embung Cihaniwung (Talun Santosa), Embung Cicoledas (Malabar), dan Embung Cikinceuh (Kertamanah).

\section{DAFTAR PUSTAKA}

Corio, Dean. Kiki Khananda. Khansa Salsabila S. 2019. Analisa Potensi Embung ITERA sebagai Pembangkit Listrik Tenaga Pico Hydro (PLTPH). Teknik Elektro, Institut Teknologi Sumatera. Jurnal Nasional Teknik Elektro, Vol. 8 No. 3, November 2019. 97-103.

Kartodirdjo, Sartono dan Djoko Surjo. 1991. Sejarah Perkebunan di Indonesia: Kajian Sosial Ekonomi. Yogyakarta: Aditya Media.

Kinacultuur, De Indienstellingen van Inlandse Personen bij de gouvernements kina Onderneming 1895-1901 (Algemene Secretarie Grote Bundel Besluit 1891-1942, No. Invetaris: 835)
Munandar, Agus Aris 2012. Kebudayaan Asutronesia sebagai Akar Peradaban Nusantara: Ornamen pada Nekara dan Artefak Perunggu lainnya. Majalah Arkeologi Indonesia. FIB UI, Depok 2012

Nuralia, Lia. 2019. PPt dalam Evaluasi Hasil Penelitian Arkeologi (Ehpa) Nasional. Jakarta: Puslit Arkenas

Nuralia, Lia. 2019. Laporan Penelitian Arkeologi Bangunan dan Produksi Perkebunan Kina Kabupaten Bandung Barat dan Sekitarnya, Provinsi Jawa Barat Abad XIX-XX. Bandung: Balai Arkeologi Jawa Barat (tidak diterbitkan).

Picture from The Archives of the Royal Tropical Museum Amsterdam) (Dokumentasi Rumah Manajer Perkebunan Kertamanah, 2019)

Winarno, Basuki dan Amdhika Putra Widyadharma. 2018. Air Embung Sumber Energi Alternatif Untuk Pembangkit Listrik. Politeknik Negeri Madiun. Journal of Electrical Electronic Control And Automotive Engeenering/JEECA) (Vol. 2, No. 3, November 2018: 213-216).

Wulandari, Ratri. 2019. PPt. dalam Sosialisasi Hasil Penelitian Arkeologi Balai Arkeologi Jawa Barat. Bandung.

Van Dr. C. JJ. Van Gall en C. Van De Koppel.1946. De Lanbouw In Den Indischen Archipel I; De Landbouw In Den Indischen Archipel, Uitgeven Onder Redactie In drie deelen. Deel 1, Algemeen Gedelte )

Van Dr. C. JJ. Van Gall en C. Van De Koppel. 1946. De Lanbouw In Den Indischen Archipel IIa; De Landbouw In Den Indischen Archipel, Uitgeven Onder Redactie. In drie deelen. Deel IIa, Algemeen Gedelte.MCMXLVI) 
HASIL DISKUSI

Pertanyaan

1. Lucas Wattimena (Balai Arkeologi Maluku)

Sistem perkebunan yang dipresentasikan memperlihatkan model manajemennya saja, apakah dapat disampaikan sejarah proses perkebunan tersebut? Mungkin juga lebih baik memperlihatkan model manajemen perkebunan tersebut?

\section{Jawaban}

1. Sejarah dan model manajemennya telah diterangkan secara lengkap dalam laporan hasil penelitian. Pada presentasi kali ini saya sengaja melewatkan untuk menyesuaikan dengan waktu yang disediakan. Penulisan makalah nanti akan diuraikan secara singkat mengenai sejarah dan model manajemen perkebunan, dengan tetap fokus pada jejak Austronesianya. 